\title{
JORNALISMO E TRANSMIDIAÇÃO
}

\author{
JOURNALISM AND TRANSMEDIA
}

\author{
Denis Porto Renó ${ }^{1}$ \\ Recebido em 23/10/2011 \\ Aceito em 29/11/2011
}

\begin{abstract}
RESUMO
Os estudos sobre comunicação seguem por distintos caminhos, inclusive no campo das tecnologias digitais. Especialmente no campo das redes sociais e da narrativa transmídia, há uma grande diversidade de estudos, mas a maioria direcionada ao campo da ficção, enquanto o jornalismo segue sem estudos práticos específicos. Este artigo apresenta os primeiros dados de um estudo teórico-prático sobre jornalismo e narrativa transmídia que contempla as redes sociais e os dispositivos móveis. Para tanto, adotamos como metodologia o método quase-experimental. Esperamos proporcionar, a partir deste estudo, novos olhares sobre o tema.
\end{abstract}

Palavras-chave: Jornalismo. Comunicação. Narrativa transmídia. Audiovisual. Novas tecnologias digitais.

\begin{abstract}
Communication studies follow different paths, including the field of digital technologies. In the field of social networks and transmedia narratives, in particular, there is a wide variety of studies, but most of them refer to fiction, whereas journalism does not develop empirical studies. This paper presents the first data from a theoretical and practical study on journalism and transmedia narrative that includes social networks and mobile devices. To this end, the study adopted the quasi-experimental method. It is expected that this study can provide new insights on the subject.
\end{abstract}

Keywords: Journalism. Communication. Transmedia narrative. Audiovisual. New digital technologies.

\footnotetext{
${ }^{1}$ Jornalista e documentarista, com mestrado e doutorado em Comunicação Social pela Universidade Metodista de São Paulo e pós-doutorado em Jornalismo Transmídia pela Universidade Complutense de Madri. É professor associado do Programa de Jornalismo e Opinião Pública da Escola de Ciências Humanas da Universidade do Rosário, Bogotá (Colômbia). É membro da RAIC - Rede Acadêmica de Investigadores em Comunicação e membro fundador da Red INAV - Rede Ibero-americana de Narrativas Audiovisuais. E-mail: <denis@ojosenelmundo.com>
} 


\section{Introdução}

As mudanças na circulação de informação têm provocado mudanças também em diversos veículos de comunicação. Importantes publicações, como a tradicional revista National Geographic, têm trabalhado em projetos de produção de conteúdos multimídia. Ao mesmo tempo, estes veículos buscam soluções para a mudança da publicidade, fundamental para a manutenção destes espaços. O cenário também tem provocado estudos sobre a possibilidade de trabalhar com jornalismo colaborativo, ou seja, com o conceito defendido por Dan Gillmor (2005), pelo qual nós somos os meios em potencial e podemos produzir conteúdo para distintos espaços comunicacionais.

Embora alguns veículos de comunicação busquem soluções apoiadas nas mudanças dos processos comunicacionais, isto não tem sido suficiente, pois muito do que podemos observar nos processos onde há uma estrutura multimídia não é algo projetado. Efetivamente, os conteúdos multimídia estão na rede, mas não há uma explicação de como se chegou a isso. Em uma conferência apresentada em 26 de julho na Universidade do Rosário, o ex-presidente da National Geographic e jornalista John Griffin declarou que isto ocorre nesta publicação. Segundo ele, na revista existe o conteúdo multimídia, destinado especialmente aos dispositivos móveis e à internet, mas não se faz um projeto antes de fazer o conteúdo, faz-se uma reorganização dos conteúdos produzidos para que seja possível proporcionar aos leitores a interatividade, mas sem planejar tudo antes.

O que declarou Griffin fortalece o conceito de que não tem sido suficiente o que temos à disposição nos espaços multimídia para que seja construída uma narrativa transmídia nos conteúdos jornalísticos disponíveis. Isto já ocorre na ficção, mas no jornalismo a estrutura narrativa ainda está muito longe do que seja necessário para que a transmidiação seja uma realidade.

Por outro lado, há no mercado de trabalho um crescente espaço para comunicadores e, especialmente, jornalistas, que saibam trabalhar com as redes sociais e com conteúdos multimídia. Ou seja, há uma demanda de mercado, mas não há um estudo sobre como produzir conteúdos que atendam a esta demanda. Além disso, empresas apostam na criação e desenvolvimento de redes sociais como ferramentas destinadas a jornalistas, como Facebook, Google+ e Twitter. Também se produzem tecnologias para a produção de conteúdo a partir de telefones celulares, e a adoção destes dispositivos tem sido estudada por importantes empresas de comunicação, como a Rede Globo, que desenvolve um manual sobre como utilizar o iPhone 4 para produzir reportagens para televisão. Este manual faz parte de uma programação de treinamentos destinados a todos os jornalistas que trabalham no grupo, e não somente nas tradicionais equipes de reportagem.

Este artigo apresenta conceitos e procedimentos para que se possa produzir conteúdo informativo verdadeiramente interativo e que contemple os conceitos de transmidiação. Para tanto, apresento os dados levantados na primeira etapa de meu estudo sobre o tema, apoiados em resultados do experimento-piloto.

\section{Interação e interatividade}

Ainda que não seja novidade o tema, o conceito sobre as distinções entre interação e interatividade é questionado entre teóricos que acreditam em significações divergentes. Para uns, o conceito é algo simples, mas para outros a interatividade é algo complexo, assim como a interação, como argumenta Lev Manovich (2005). Outro questionamento é apontado por Alex Primo (2007), que defende a inexistência de interatividade, e que tudo é interação.

Adotamos a definição de Cameron (apud SHAW, 2005, p. 372), para quem "o usuário, através de novos caminhos, adquire novas experiências", ou seja, por meio da definição de seus caminhos dentro de um labirinto, o usuário adquire suas próprias experiências. Quanto mais fragmentos existirem, mais possibilidades de combinação existirão no processo comunicacional, na oferta de discurso.

A interatividade está presente em qualquer processo comunicacional, mesmo que unidirecional. Ela ocorre, por exemplo, na recepção da mensagem e sua interpretação. $\mathrm{O}$ ato de interpretar é interativo. Porém, é um processo interativo que pode se limitar à consciência do receptor. Ele não reage, não interage a essa recepção de outra forma a não ser a de se conscientizar a respeito. 
De acordo com Vilches (2003, p. 229), "a interatividade não é um meio de comunicação, mas uma função dentro de um processo de intercâmbio entre duas entidades humanas ou máquinas".

Na pós-modernidade, limitar-se a conscientizar a respeito de algo é pouco. É preciso participar do processo, de alguma forma, ter a liberdade de escolher os caminhos a seguir (BAUMAN, 2001), ou então participar diretamente da construção do produto final como coautor da obra (MANOVICH, 2005). São características presentes na sociedade pós-humana (SANTAELLA, 2007) que foram, ou devem ser, absorvidas pelos processos comunicacionais contemporâneos.

Existem diversos tipos de interatividade, e talvez seja esse o temor de alguns teóricos pela definição literal do conceito, por acreditar que isso seja algo generalista, como ressalta Manovich (2007).

$\mathrm{O}$ autor apresenta diversas definições sobre interatividade, que vão desde as mais simples divisões, como abertas ou fechadas, até mesmo as estruturas mais complexas, apresentadas pelas modalidades arbórea (por menus), escalabilidade, simulação, interface da imagem e imagem instrumento.

Dentre as opções de interatividade apresentadas por Manovich, destaca-se a interatividade arbórea, também conhecida como interatividade por menus, que recebe o nome por apresentar as opções na interface (tela do usuário) como se fossem galhos de árvore. Esta é mais comum, mas podem ser encontradas as outras interatividades. Paralelas, encontram-se as interatividades abertas e fechadas que, para o autor, distinguem-se por oferecerem produtos comunicacionais diferentes. Enquanto a aberta apresenta possibilidades diversas, como a programação informática procedimental e por objetos até a inteligência artificial e redes neurais, a fechada apresenta os elementos fixos e dispostos em uma estrutura arbórea (MANOVICH, 2005, p. 87).

Outra proposta importante sobre os tipos de interatividade é apresentada por Primo (2007) como uma revisão com relação aos conceitos de interatividade. Para este autor, deve-se reavaliar se os conceitos de interatividade, ou interação, como ele defende, são os mesmos de processos interativos ou de processos reativos, termos propostos por Williams (apud PRIMO, 2007, p. 27). Segundo o autor, o resultado de um processo reativo é predeterminado, o que limita a participação. Porém, existem níveis de interatividade, como definidos por Manovich (2005), o que desmistifica a crítica com relação ao processo reativo. Além disto, dependendo da quantidade de possibilidades, o próprio Primo (2007, p. 27) apresenta diretrizes que defendem essa perspectiva de quantidade de possibilidades. Segundo ele, "[...] a grande maioria dos recursos hoje listados como serviços interativos no contexto televisivo, caem no que Williams chamaria de reativo. Tais serviços resumem-se a oferecer algumas opções predeterminadas para seleção". Ora, a distância entre algumas e muitas pessoas é algo relativo, mas pode ser expressiva.

\section{Navegação hipertextual pela transmídia}

Para pensarmos neste trabalho, precisamos compreender alguns conceitos. Um deles é sobre conteúdos digitalmente expandidos. Um ambiente hiper é um espaço expandido. No campo do eCommunication, como propõe José Luis Orihuela (2004), ele é construído a partir de links "inteligentes", ainda que a inteligência esteja mesmo nos autores do roteiro narrativo destes espaços.

Mas o mundo midiático vive mudanças inclusive pelo surgimento dos espaços hiper. Neles mudou a forma de produzir conteúdo por quem produz o conteúdo, porque se produz o conteúdo e para quem se produz. Com isto, novos estudos têm contemplado este novo cenário, inclusive porque há uma necessidade mercadológica, e não somente narrativa, para isto.

Scolari, no livro Hipemediações, apresenta um novo olhar sobre os conceitos já conhecidos das teorias da comunicação, pois, para ele, as mudanças tecnológicas não chegam somente na estrutura dos meios, mas também, e acertadamente, nos processos, nas linguagens e nas relações entre emissor e receptores. $\mathrm{O}$ autor ainda defende um novo cenário comunicacional sobre isto, onde a comunicação massiva deixou de existir e agora existe a comunicação democrática, muitos a muitos, onde nós podemos ser os meios, como defende Dan Gillmor (2005).

Desta forma, o digitalmente expandido se expande até as redações. Mas fica uma pergunta importante: como estão os processos de produção de conteúdo jornalístico para os meios digitalmente expandidos? E, junto, chega outraperguntaigualmente 
importante: as redações estão preparadas para experimentar e/ou praticar estes novos processos de produção? O que percebo é uma distância defensiva, ainda que o cenário esteja mudando, das redações frente aos novos formatos. Existem profissionais mais perto da realidade, e este grupo está crescendo, mas o ideal seria um crescimento e um desenvolvimento mais perto das redações, e não como ocorre, mais na academia. Pois, desta forma, as redações deixarão de existir, ainda que, como comenta Scolari (2008), a história sempre presenciou a chegada de um novo meio e a absorção dos antigos pelo novo, e não o desaparecimento. Mas as redações não são um meio. Representam uma forma de fazer noticia, mas não é a única. Imagino que se as redações começarem a absorver de forma expressiva as tendências sociais a sociedade tomará o posto dela e começará a produzir conteúdos por sua conta, como já ocorre, de certa forma.

Além disso, de acordo com Scolari (2008), os espaços midiáticos vivem outra realidade: uma convergência, representada por três tecnologias - telefone, televisão e computador. Estes três juntos ocupam, cada dia mais, o mesmo espaço. Agora temos uma televisão na internet, através de sites desenhados a partir de conceitos de redes sociais, como YouTube e Vimeo. Ao mesmo tempo, temos computador dentro do telefone celular, como os smartphones. Por fim, temos a televisão dentro dos telefones celulares. Ou seja, tudo em um equipamento pequeno, portátil e constantemente conectado: a mobilidade. (AUGÉ, 2007).

Defino hipertexto como um ambiente de leitura não linear que oferece ao usuário a possibilidade de criar seus caminhos de arquitetura de leitura. Aarshet (2005, p. 85) define o hipertexto como uma "ferramenta para a mente", onde se desenvolve a estrutura desejada de acordo com suas opções cognitivas. O mesmo ocorre com a hipermídia, um ambiente hipertextual que reúne uma diversidade de informações multimidiáticas (foto, áudio, vídeo, animação, infográfico, etc), além do texto, proporcionando ao receptor/usuário a possibilidade de escolha de seus próprios caminhos narrativos. Tanto o hipertexto como a hipermídia são processos interativos, pois proporcionam ao usuário a escolha de seus caminhos para obter suas novas experiências, de acordo com sua vontade. Estes são ambientes líquidos, fluidos, participativos, autônomos (BAUMAN, 2001; SANTAELLA, 2007).

George Landow (2009) define como características fundamentais do hipertexto a topologia, a multilinearidade, a reticularidade e a manipulação. Isto está nos ambientes hiper, interativos que proporcionam o mecanismo, como internet e telefones celulares, considerados ambientes contemporâneos.

Entre as características apresentadas por Landow, destaca a topologia, que possibilita ao hipertexto uma compreensão do significado, e isto independe dos caminhos de leitura. É necessário que o receptor/usuário tenha a possibilidade de, lendo uma parte, compreender minimamente o conteúdo. Cada fragmento é independente dos outros, ainda que exista uma relação com eles.

A multilinearidade tem a ver com a topologia, mas o receptor/usuário pode escolher entre continuar lendo ou mudar para outro texto. Nos dois casos, os procedimentos serão corretos. Através dos links, é possível a navegabilidade entre os conteúdos fragmentados, mas dentro do hiperespaço, nome do ambiente onde estão as estruturas hipertextuais. Isto possibilita ao hipertexto uma característica fundamental: uma possível leitura sem começo, meio ou final. É a liberdade de leitura proporcionada ao leitor, que pode começar e concluir onde quiser e, além disto, pode inclusive mudar para outros textos. Mas a reticularidade também oferece essa possibilidade de "olhar" o conteúdo através de caminhos distintos. Nesta perspectiva, defino a narrativa hipertextual como o modo livre de leitura, onde a forma é decidida pelo receptor/usuário. Um ambiente onde o receptor tem o controle e a liberdade.

Outra característica existente nos ambientes hiper é a hipermídia. Nela, assim como os textos inter-relacionados, existem vínculos com outros tipos de fragmentos comunicacionais. Temos discussões importantes a partir de George Landow (2009, p. 25), na revisão do livro Hipertexto 2.0. (agora denominado Hipertexto 3.0.), propondo que "a expressão hipermídia simplesmente estende a noção de texto hipertextual ao incluir informação visual e sonora, assim como a animação e outras formas de informação". Mas o autor, no mesmo livro, decide não fazer distinções entre hipertexto e hipermídia, por crer que eles fazem parte de um único grupo que proporciona ao leitor uma atividade avançada nos processos de leitura-participação. 
Considerada como a estrutura popular da eCommunication, a hipermídia tem seu ápice com a convergência de mídias, em que ficou ainda mais possível interatuar e definir os caminhos labirínticos de leitura. Segundo Lorenzo Vilches (2003, p. 17):

A migração digital diz respeito, em primeiro lugar, a sujeitos interconectados que chegam a uma nova fronteira da comunicação e do real. A nova fronteira, que alguns chamam de ciberespaço, é um novo espaço de pensamento e de experiências humanas, formado pela coabitação dos antigos e novos formatos de hiper-realidade.

O receptor/usuário busca cada vez mais os espaços com possibilidade de leitura através de multilinguagem, seja na televisão, no cinema, na literatura ou na internet. Por este motivo, a comunicação televisiva vive um crescimento de conteúdos intertextuais, pois é a forma de ampliar as linguagens disponíveis na "caixa mágica" e compensar a falta de navegabilidade na plataforma. $\mathrm{O}$ receptor/usuário faz uma navegação pelo processo cognitivo, e não pelos fragmentos apresentados pelo meio.

Agora a comunicação vive um momento de hipermediações (SCOLARI, 2008, p. 116), compreendida como o tempo dos suportes digitais e estruturas hipertextuais, em que o usuário é um colaborador com alta interatividade com a interface. Seus espaços são os virtuais, como a blogosfera e ambientes Wiki, e suas linguagens se apoiam na multimidialidade (NEGROPONTE, 1995). Ao mesmo tempo, Landow (2009) define que nos espaços onde a multimidialidade está presente os leitores são ativos, ou então leitores-escritores. A mesma definição é feita por Renó \& Gonçalves (2007), mas denominado coautores, conceito também presente em Scolari (2008).

Ambientes hipermidia adotam, com alta intensidade, o conceito de intertextualidade defendido por Bakhtin e Kristeva, em muitas de suas obras. Segundo Bakhtin (1986), intertextualidade é o diálogo entre inúmeros textos. Por isto, George Landow (2009, p.467) aponta, sobre intertextualidade, que são as referências recíprocas dentro de um texto ou metatexto concebido como obra. Entretanto, o autor observa que isto foi empregado pela primeira vez por Tzvetan Todorov, em 1969.

Podemos comparar esta definição com o conceito de hipermídia definido por Landow. Mas é importante recordar que as definições apresentadas sobre intertextualidade acontecem em um tempo onde a hipermedialidade que conhecemos hoje não existia para o público em geral. Por isto, podemos considerar que Bakhtin e Landow falam sobre a mesma coisa, claro que em tempos historicamente, sociologicamente e tecnologicamente distintos.

Entre as linguagens especificas propostas para as redes sociais e a blogosfera, destacam-se a póshipertextualidade e a transmidiação. Sobre os novos termos existentes a partir do desenvolvimento dos meios digitais, Scolari propõe uma reflexão que tem sua aplicabilidade a especificamente estes dois. De acordo com o autor:

Perguntamo-nos se realmente vale a pena forçar os dicionários teóricos ao invés de recuperar termos anteriores da chegada dos meios digitais como a noção semiótica de intertextualidade - já integrados dentro de um corpo epistemológico consolidado e amplamente trabalhados nas últimas décadas. (SCOLARI, 2008, p. 109).

Sobre estes termos, podemos destacar o surgimento da terminologia Transmídia, inicialmente proposta por Stuart Saunders Smith (1975), a partir do termo trans-media music, que apresentava uma mescla de melodias distintas em uma única obra. Depois o termo foi utilizado no campo da comunicação por Marsha Kinder (1991), denominando-a de intertextualidade transmídia. Ainda que não seja o objetivo deste estudo (justificar ou criticar a criação de um novo termo), creio que devemos refletir sobre os novos nomes que as coisas nos meios digitais recebem. Como Scolari propõe, quem sabe seja desnecessário utilizar novos nomes para as mesmas coisas.

Sobre pós-hipertextualidade, Scolari (2008) desenvolve um texto que faz uma recomposição da televisão até a hipertelevisão, com a adoção de muitas telas dentro de uma única tela, como o seriado 24 horas ou no noticiário televisivo $\mathrm{CNN}$. Ao mesmo tempo, utilizam-se conteúdos intertextuais, fazendo com que o receptor possa "navegar" pelos links existentes na narrativa. São características pós-modernas, pelas quais a sociedade líquida busca sempre multicaminhos e multicanais para os multiconteúdos (ainda que Zygmunt Bauman, o precursor do tema, não considere o tempo em que vivemos como pósmodernidade). 
Entre as características pós-modernas da pós-hipertextualidade está a narrativa transmídia, conhecida também como transmediação, transmedia storytelling, ou somente transmídia. Entretanto, suas origens estão enraizadas na intertextualidade e têm como proposta a reconstrução cognitiva a partir de múltiplas plataformas.

Entre os problemas no campo deste novo panorama da comunicação está a localização lógica e natural do Jornalismo. Segundo Cebrián Herreros \& Flores Vivar (2007), algumas funções devem desaparecer e, além disso, outras estão surgindo, como a do jornalista especializado em espaços colaborativos. Além disto, os jornalistas devem saber produzir conteúdos hipermidiáticos e transmidiáticos (RENÓ, 2011). Os jornalistas para estes espaços, denominados por Scolari como jornalistas multiplataforma, devem possuir distintos conhecimentos (SCOLARI, 2008, p. 207):

- Polivalência tecnológica: o profissional da informação utiliza instrumentos (software e hardware) que permitem produzir e organizar conteúdos em diferentes suportes. Por exemplo, o jornalista domina ao mesmo tempo aplicações de texto, retoque fotográfico, edição não linear de vídeo ou base de dados;

- Polivalência midiática: o profissional da informação desenha e produz conteúdos em diferentes linguagens (texto, áudio, gráfico, vídeo e interativo). O jornalista, depois de cobrir um evento, prepara o texto para enviá-lo aos meios impressos ou online, grava uma intervenção radiofônica e edita o vídeo para transmitir em televisão. Nesta polivalência existem conhecimentos tecnológicos (conhecimento dos instrumentos) e semióticos (conhecimento das linguagens dos diferentes meios);

- Polivalência temática: um mesmo profissional da informação se ocupa de gerar informações para as diferentes seções do meio (esportes, cultura, etc).

Percebo, a partir destas definições de Scolari, que os jornalistas necessitam preparar-se para o novo cenário da comunicação informativa, inclusive pela realidade atual.Énecessário, além dos conhecimentos apresentados pelo autor, saber produzir conteúdos que tenham uma estrutura transmídia, para que a sociedade contemporânea possa navegar pelas informações intertextuais modernas. Não é lógico repetir a mesma forma de outros meios para os multimeios, especialmente com uma narrativa transmídia. E ainda que pareça obscuro seu significado, o tema transmídia é definido com clareza por Jenkins (2008, p. 135):

Uma história transmídia se desenvolve através de múltiplos suportes midiáticos, com cada novo texto contribuindo de maneira distinta e valiosa para o todo. Na forma ideal de narrativa transmídia, cada meio faz o que faz de melhor - a fim de que uma história possa ser introduzida em um filme, ser expandida para a televisão, novelas e HQ; seu universo possa ser explorado em videogames ou experimentado como atração em um parque de diversão.

Enquanto Jenkins apresenta conceitos esclarecedores sobre o tema, Scolari conclui a discussão com algumas perguntas que necessitam ser respondidas. Se não as respondemos, nem naturalmente, e tampouco academicamente, teremos problemas com o futuro da produção comunicacional. Scolari (2008, p. 235) questiona:

Onde se reposiciona a televisão na Media Ecology? Como se posiciona a respeito dos computadores ou dos telefones celulares? Como se cria socialmente o significado da televisão na era das telas interativas?

Se tivermos as respostas podemos ficar mais tranquilos e começar a produzir conteúdos. Se não temos, podemos nos preocupar, porque em pouco tempo não saberemos mais como produzir conteúdos para estes meios. O que sabemos, seguramente, é que a sociedade está cada dia mais imersa no eCommunication, proposto por Orihuela, e os processos devem mudar de acordo com as mudanças sociais.

Inúmeros estudos necessitam de um desenvolvimento, a começar por uma revisão das teorias de comunicação, válidas para os antigos meios, mas questionáveis para os digitais, como aponta Scolari (2008) em quase todo seu livro. Além disso, necessitamos mudar linguagens, pois agora são outros conteúdos, por outros meios, e para outros públicos, que conquistaram o status de coautor, de participante. Os seres-meio, como aponta Dan Gillmor (2005), produzem suas "notícias", deixaram de ser fontes para jornalistas e passaram a ser fontes para a sociedade 
a partir de seus espaços virtuais, seja pela blogosfera, seja por rede social ou por Twitter. Cidadãos que fazem a circulação da informação por sua própria força, e com suas próprias palavras e línguas. Aos jornalistas não agrada pensar nisso, mas é uma nova forma de fazer o factual, e o jornalista ficou com a possibilidade de fazer as reportagens, com mais profundidade no tema, e com mais técnica e tempo para fazer o que historicamente sabe melhor: contar histórias.

\section{A arquitetura da informação}

A forma de produzir conteúdo transmídia para redes sociais e blogosfera exige mais dos autores. Não se produz como antes. Existe uma necessidade distinta de se projetar, planificar os caminhos e os conteúdos distintos para, ao final, produzir. É necessário produzir um roteiro multimídia, definido por George Landow (2009) como mensagens hipermidiáticas.

Para este roteiro multimídia, proponho a construção, acima de tudo, de uma estrutura que denomino Fluxograma Algorítmico Circular Rizomático (RENÓ, 2011). Este fluxograma consiste em pré-construir, visualmente, os caminhos e os conteúdos possíveis e necessários para depois sair para a produção de conteúdos, efetivamente. É um roteiro visual que permite experimentar os distintos caminhos dos conteúdos e as relações entre eles para depois produzir de forma mais eficaz.

Fluxograma Algorítmico Circular Rizomático

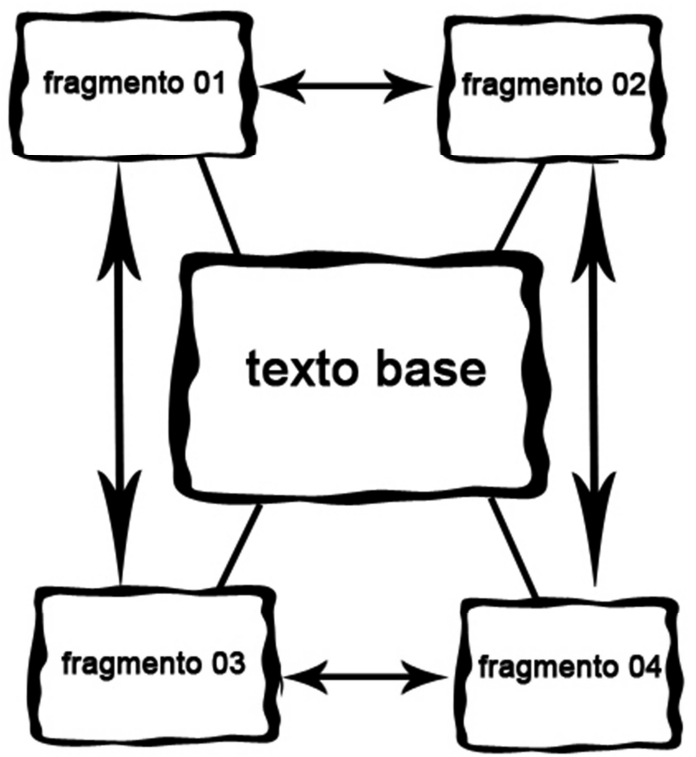

Vicente Gosciola (2008) defende a necessidade de se produzir um roteiro para depois sair em produção do conteúdo interativo. Desta forma, é viável otimizar a produção e o tempo, inclusive. Assim, é possível ter uma melhor construção transmídia. Mas, na verdade, de acordo com Jenkins (2009, p. 44), a construção transmídia já ocorre dentro do cérebro humano, naturalmente, por uma evolução intelectual da sociedade.

Outro parâmetro de produção refere-se às ferramentas possíveis para se produzir conteúdos transmidiáticos para redes sociais e blogosfera: dispositivos móveis. Para tanto, foi experimentado o telefone celular iPhone, modelo 3GS, que permite a produção audiovisual, inclusive o processo completo de edição, assim como fotografias de qualidade e envio de textos a blogs e redes sociais.

Para produzir conteúdos audiovisuais, foi utilizado o aplicativo Reel Director para a edição do fragmento informativo, a partir dos materiais gravados no mesmo telefone. Com estes materiais, podemos produzir um fragmento jornalístico, inclusive com crédito do repórter e/ou do entrevistado.

A produção fotográfica contou com a câmera disponível no próprio equipamento, ainda que se possam adotar aplicativos de tratamento de imagem, como o Adobe Photoshop Express. A partir disto, é possível tratar as imagens registradas para depois enviar às plataformas comunicacionais.

Por fim, a produção do texto é viável a partir do aplicativo BlogPress, que ao final permite que o texto tenha fotos e vídeos, tanto os disponíveis no arquivo do telefone como a produção de novos conteúdos (vídeo e/ou foto). Também permite que seja criado um link do texto no Twitter e no Facebook, automaticamente, e a cópia do link para disponibilizar no Google+. Com isto, é possível fazer a distribuição de conteúdos informativos por redes sociais a partir de um telefone celular, atendendo a outro conceito transmidiático: a mobilidade.

\section{Considerações}

As mudanças sociais fazem com que mudemos as formas de viver. É o que acontece com a alimentação, com as formas de entretenimento e, obviamente, com as formas de comunicação. Isto já ficou claro entre os profissionais quando o tema 
é ficção, provavelmente porque estão diretamente envolvidos com o mercado. Entretanto, ainda que seja necessário, no campo do jornalismo não há uma definição ou uma evolução para tanto, como há na ficção. Contudo, é possível desenvolver uma forma de se produzir conteúdo para os meios hipermidiáticos e para a sociedade contemporânea.

Esta realidade encontra-se na narrativa transmídia, assim como nas redes sociais e na blogosfera. Nestes espaços, é possível desenvolver conteúdos que atendam às aspirações da sociedade pós-moderna. Ainda sobre esta sociedade, é necessário planejar conteúdos que sejam interativos, ou seja, que ofereçam à sociedade a possibilidade de participação, de coautoria na informação. Para tanto, é fundamental desenvolver o fluxograma rizomático.

Mas há outro ponto fundamental e que deve ser explorado pelos jornalistas, especialmente: os dispositivos de telefonia celular, que podem ser uma possibilidade para o jornalista, e já assumem este papel em diversas redações jornalísticas. Na verdade, é uma realidade que somente os mais conservadores, denominados por Carlos Scolari como dinossauros da comunicação, insistem em evitar. Mas é inevitável, e quem não aceitar isto pode perder seu espaço no mercado da comunicação jornalística, onde a agilidade na produção de conteúdo é algo fundamental, ainda que não seja o mais importante.

\section{REFERÊNCIAS}

AUGÉ, Marc. Por una antropología de la movilidad. Madrid: Gedisa, 2007.

BAUMAN, Zygmunt. Modernidade líquida. Tradução de Plínio Dentzien. Rio de Janeiro: Jorge Zahar Editores, 2001.

CASTELLS, Manuel. A sociedade em rede. São Paulo: Paz e Terra, 1999.

GILLMOR, Dan. Nós, os media. Lisboa: Editorial Presença, 2005.

GOSCIOLA, Vicente. Roteiro para as novas mídias: do cinema às mídias interativas. São Paulo: Editora SENAC, 2008.

JENKINS, Henry. Cultura da convergência. 2.ed. São Paulo: Aleph, 2009.

KUNCZIK, Michael. Conceitos de jornalismo. São Paulo: Com-Arte, 2001.

LANDOW, George. Hipertexto 3.0. Madrid: Paidós Ibérica, 2009.
ORIHUELA, José Luis. Mundo Twitter. Barcelona: Alienta Editorial, 2011.

ORIHUELA, José Luis. eCommunication: the 10 paradigms of media in the digital age. In: SALAVERRÍA, Ramón; SÁDABA, Charo (Eds.). Towards new media paradigms: content, producers, organizations and audiences. Pamplona: Ediciones Eunate, 2004.

PRIMO, Alex. Interação mediada por computador: comunicação, cibercultura, cognição. Porto Alegre: Sulina, 2007.

RENÓ, Denis. Cinema interativo e linguagens audiovisuais interativas: como produzir. Tenerife: Editora ULL, 2011.

SCOLARI, Carlos. Hipermediaciones: elementos para una teoría de la comunicación digital interactiva. Barcelona: Gedisa, 2008.

SHAW, Jeffrey. O cinema digitalmente expandido: o cinema depois do filme. In: LEÃO, Lúcia. O chip e o caleidoscópio: reflexões sobre as novas mídias. São Paulo: SENAC, 2005.

VILCHES, Lorenzo. A migração digital. São Paulo: Loyola, 2003. 